\title{
Stenting deferral in primary percutaneous coronary intervention: exploring benefits and suitable interval in heavy thrombus burden
}

\author{
Ahmed M. Magdy ${ }^{1 *}$, Salwa R. Demitry ${ }^{2}$, Hosam Hasan-Ali ${ }^{2}$, Mohamed Zaky ${ }^{2}$, Mohamed Abd El-Hady ${ }^{1}$ and \\ Mohamed Abdel Ghany²
}

\begin{abstract}
Background: Deferred stenting, despite being successful in early studies, showed no benefit in recent trials. However, these trials were testing routine deferral; not in patients with heavy thrombus burden.

Results: This is a prospective, Randomized Clinical Trial that included 150 patients who presented with STEMI, patients were allocated into three equal groups after the coronary angiography \pm primary intervention and before stenting of the culprit lesion; group (A) included 50 patients with early deferral of stenting, group (B) included 50 patients with late deferral and group (C) included 50 patients with immediate stenting. No-reflow was significantly higher in group $C$, while Final TIMI flow grade 3 and MBG grade 3 were significantly higher in group $A$ and $B$ than group $C_{;} p=0.019$ and $<0.001$ respectively, with no significant difference between groups $A$ and $B$, only the thrombus resolution in group $B$ was significantly higher than group $A ; p<0.001$. Finally, 6-months, over-all MACE was significantly higher in group C (34.7\% vs. $14.6 \%$ and $16.3 \%, p=0.029)$.

Conclusions: Stent deferral was proved to be better than immediate stenting after recanalization of IRA, in achieving TIMI III flow, reducing risk of 6 months MACE, and restoration of myocardial function in a subset of STEMI patients presenting with large thrombus burden. While, no significant difference was found between both deferral times in final TIMI flow, or clinical outcomes.
\end{abstract}

Keywords: Deferral, ST-segment elevation, Myocardial infarction, Slow-flow, No-reflow

\section{Background}

Primary percutaneous coronary intervention (PCI) with stent implantation is the current standard treatment for patients with ST-segment elevation myocardial infarction (STEMI) [1]. However, even when revascularization of the occluded vessel appears successful, distal embolization can occur, which leads to microvascular dysfunction, and is associated with an unfavorable prognosis [2]. Therefore, a considerable number of patients with STEMI treated with primary PCI shows reduction in

\footnotetext{
*Correspondence: a magdy82@hotmail.com

${ }^{1}$ Cardiovascular Medicine, National Heart Institute, Cairo, Egypt Full list of author information is available at the end of the article
}

blood flow in the culprit artery, that usually occurs after stent implantation. Even in patients with normal epicardial flow, myocardial perfusion may be impaired [3, 4]

Distal embolization during lesion manipulation was thought to be a major cause of no-reflow, yet, using distal protection devices didn't prove to be of value $[5,6]$, and thrombectomy seems beneficial in some settings, but in others it may increase infarct size $[7,8]$.

Stent implantation timing remains a controversial issue, as immediate stenting in a thrombotic context is associated with many risks [9]. Immediate stenting was found to be associated with no-reflow, distal embolization by thrombus, and impairment of myocardial perfusion [10-12]. This has led investigators to defer stenting 
when artery patency was obtained. This strategy was proposed in some earlier studies with some success $[13,14]$. The deferred stenting after restoration of normal epicardial flow by immediate intervention (MIMI) by Isaac et al. [13] proposed the idea of stenting deferral in STEMI. The idea that was explored by other studies afterwards, with better procedural end results, short and long-term results as better left ventricular function and lower incidence of MACE in comparison with immediate stenting [13, 15-17]. Carrick et al. [16], found that deferred stenting in primary PCI reduced no-reflow and increased myocardial salvage compared with conventional primary PCI with immediate stenting. Randomization was to either perform immediate stenting or deferral of stenting after recanalization by $4-16 \mathrm{~h}$ interval [16]. Also, the INNOVATION trial showed that patients randomly assigned to stenting 3 to 7 days after their initial procedure for STEMI "had a strong tendency" toward reduction in infarct size, as well as reduced microvascular obstruction (MVO) versus those managed with immediate stenting [18].

In contrast, recent results from new randomized controlled trials (RCTs), showed some inconsistent results compared with previous observational studies. However, these trials were testing routine deferral and not in a special subset $[19,20]$. To get a clearer view of this controversial issue, our study aimed to investigate the beneficial deferral time of stenting in 1ry PCI after recanalization of the infarct related artery in a specific subset of patients presenting with heavy thrombus burden who are expected to have a higher risk of no-reflow with immediate stenting. Aiming to gain benefit from the fact that delayed stenting may carry the following advantages; decreasing rates of angiographic events (distal emboli, no-reflow) with reduced infarct size which gives time to assign the most appropriate treatment strategy (stent vs. coronary artery bypass grafting vs. medical therapy alone), noting that neither stent nor PTCA were needed in $10 \%$ of patients allowing statin preloading before angioplasty in addition to the possible reduction in congestive heart failure, re-infarction and death [21-23].

\section{Methods}

This is a prospective, Randomized Clinical Trial that included 150 patients who presented with STEMI. The study was held in the period from 2016 to 2019.

Block Randomization was used in this study; prior to the beginning of the study, a simple random sample through Microsoft Excel 2010 was done to randomly select one of the sequences of block of $3(\mathrm{~A}, \mathrm{~B}, \mathrm{C})$ to determine intervention that will be received by the first three patients eligible for the study, then the following sequences of block were randomly selected the same way and this was repeated till 50 blocks of 3 were prepared for the 150 patients eligible for the study. Patients were allocated accordingly into three equal groups after the coronary angiography \pm primary intervention (in order to achieve TIMI II-III flow in IRA either spontaneously, by aspiration thrombectomy or by balloon dilatation) and before stenting of the culprit lesion; Group (A) included 50 patients with intention to stent the residual stenosis 4-16 h later (Early deferral). Group (B) included 50 patients with intention to stent the residual stenosis after 7 days (Late deferral). Group (C) included 50 patients treated with the standard clinical practice of immediate stenting. Blinding was non-applicable with the implemented intervention.

The included patients fulfilled the following; STEMI with symptoms of ischemia of $\leq 12 \mathrm{~h}$ duration, OR time from symptom onset $>12 \mathrm{~h}$ in the presence of ongoing symptoms suggestive of ischemia, or life-threatening arrhythmias, had a heavy thrombus burden in the infarct related artery (2-5 TIMI thrombus grade), and achievement of TIMI II-III flow in IRA before randomization. Patients were excluded if presented with cardiogenic shock, culprit lesions in unprotected left main coronary artery or saphenous vein grafts, failure to achieve TIMI flow grade II-III before randomization to either immediate stenting or deferral, patients with type $\mathrm{C}$ dissections or worse in IRA, patients who had previous myocardial infarction in the target vessel area, patients with stent thrombosis, and evidence of GIT bleeding within 1 month.

All patients were subjected to full history taking and data recording including; age, sex, risk factors like diabetes, hypertension, smoking (either former or current), positive family history for ischemic heart disease, and/or prior angina, PCI and CABG. Thorough physical examination including vital signs (pulse and blood pressure), complete general examination and local cardiac examination were performed for every patient. Resting ECG was performed paying special attention for detection of electrocardiographic criteria of STEMI, and detecting arrhythmias.

Admission serum glucose level, serum creatinine and cardiac enzymes were measured. In addition to standard routine laboratory investigation.

An echocardiogram was performed on first day of hospitalization and after 6 months, and the differences in results between both studies were compared regarding left ventricular function.

\section{Interventions}

Patients received $300 \mathrm{mg}$ aspirin, and loading dose of ticagrelor prior to coronary angiography, with heparin given before intervention. Coronary angiography 
was performed in the standard fashion; through femoral approach. Selective coronary angiography was performed. Angiographic data of the patients were obtained, which included an average of six left coronary and two right coronary artery injections giving sufficient data to enable quantitative angiography and identification of the culprit lesion [24].

After coronary angiography and inclusion of the patient due to heavy thrombus criteria, TIMI III flow was pursued in IRA (either spontaneous, using balloon angioplasty or aspiration catheter). Direct stenting was the preferred strategy, with pre-dilatation only performed when necessary. In the deferred stenting group, TIMI IIIII was accepted at the end of the 1st procedure and PCI was performed after intensive pharmacologic treatment for 4-16 the specified deferral time.

The treatment protocol for deferred patients included transferring to the Coronary Care Unit, continuous intravenous infusion of glycoprotein IIb/IIIa inhibitor for $48 \mathrm{~h}$ (Irrespective of time of deferral of stenting), administration of subcutaneous low molecular weight heparin (enoxaparin $1 \mathrm{mg} / \mathrm{kg}$ every $12 \mathrm{~h}$ until the 2 nd procedure), and double antiplatelet therapy with aspirin and ticagrelor, in addition to evidence based medical treatment according to current guidelines [25].

\section{Assessment of microvascular perfusion}

TIMI flow grade system and myocardial blush grade (MBG) were used for assessment by 2 physicians in a blinded manner [26].

\section{Follow-up}

Clinical data were collected for patients in pre-specified visits to the outpatient clinic and using telephone interviews in-between. During the initial hospital stay, the following were evaluated:

1. Incidence of Major Adverse Cardiovascular Events (MACE) including cardiac death, nonfatal reinfarction (when ST-elevation $\geq 1 \mathrm{~mm}$ recurs or new pathognomonic $\mathrm{Q}$ waves appear in at least two contiguous leads, particularly when associated with ischemic symptoms, and requires more than 20\% increase of the cTn value in the second sample) [27], arrhythmias, heart failure (defined by auscultation of 3rd heart sound, NYHA class III or more, dyspnea, or a chest X-ray denoting pulmonary congestion) and nonfatal cerebrovascular stroke.

2. The occurrence of CIN (an increase of $25 \%$ or more, or an absolute increase of $0.5 \mathrm{mg} / \mathrm{dl}$ or more in serum creatinine from baseline value, at $48-72 h$ following the exposure to contrast media) [28].

3. Bleeding (requiring transfusion).
While the occurrence of MACE was re-evaluated at 6-months follow-up as well as echocardiographic evaluation.

\section{Definitions of endpoints}

The primary endpoint was the incidence of no-reflow, defined as absence of flow (TIMI flow 0), incomplete filling (TIMI flow I), complete filling with slow flow (TIMI flow II), of the infarct related artery at the end of the procedure as evident angiographically. The secondary endpoint included angiographic parameters (i.e. MBG), echocardiographic parameters (i.e. EF by Simpson's method) and occurrence of MACE.

\section{Statistical analysis}

Analysis of data was done using Statistical Program for Social Science version 24. Quantitative variables were presented in the form of mean and standard deviation. Continuous variables were compared using Student's T test for independent groups which was used in case of normal distribution or Mann Whitney test as a non-parametric alternative. Qualitative variables were described as number and percent. Qualitative variables were compared using chi-square $\left(X^{2}\right)$ and Fisher exact test, as indicated. A $p$ value less than 0.05 was considered statistically significant.

\section{Results}

This study included 150 patients with mean age $51.5 \pm 10.5$ years; of whom males represented $77.3 \%$. Regarding the studied risk factors; almost half of the patients were smokers and hypertensive (54\% and $49.3 \%$ respectively), nearly one third of the patients were diabetic (31.3\%), 27.3\% had dyslipidemia and $9.3 \%$ of the studied sample had history of IHD. More than half of the patients were diagnosed with anterior STEMI (53.3\%), 44\% Inferior STEMI and 2.7\% Lateral STEMI. Median heart rate of the patients was 96 beats/min and their median BP was $120 / 70 \mathrm{mmHg}$. As for Killip classification; more than half of the patients were classified in class 1 (54\%), 38.7\% class 2 and $7.3 \%$ class 3 as shown in Table 1.

No significant difference was found between the studied groups regarding the baseline characteristics (age, gender, risk factors), diagnosis, clinical data (heart rate, SBP, DBP and Killip classification), baseline echocardiographic data $(\mathrm{EF})$ and creatinine level $(p>0.05)$ as shown in Table 2.

Comparison between the studied groups regarding angiographic and 1st procedural data demonstrated that there was no significant difference between the 3 groups regarding 'IRA', thrombus grade and baseline TIMI flow, ( $p$ values $>0.05)$. After the 1st procedure; the 
Table 1 Baseline characteristics of the whole study population

\begin{tabular}{ll}
\hline Baseline characteristics & All patients $(\mathbf{N = 1 5 0})$ \\
\hline Age (years) & $51.5 \pm 10.5$ \\
Risk factors & \\
Male gender & $116(77.3 \%)$ \\
DM & $47(31.3 \%)$ \\
HTN & $74(49.3 \%)$ \\
Smoking & $81(54 \%)$ \\
Dyslipidemia & $41(27.3 \%)$ \\
IHD & $14(9.3 \%)$ \\
Diagnosis & \\
Anterior STEMI & $80(53.3 \%)$ \\
Inferior STEMI & $66(44 \%)$ \\
Lateral STEMI & $4(2.7 \%)$ \\
Heart rate (beat/min) & $96(90-110)$ \\
SBP (mmHg) & $120(100-130)$ \\
DBP (mmHg) & $70(60-80)$ \\
Killip class & \\
Class 1 & $81(54 \%)$ \\
Class 2 & $58(38.7 \%)$ \\
Class 3 & $11(7.3 \%)$ \\
\hline
\end{tabular}

percentage of patients with TIMI flow grade 3 was significantly higher in groups $\mathrm{A}$ and $\mathrm{B}$ compared to group C $(90 \%$ and $92 \%$ Vs. $76 \%, p$ value $=0.034)$, however no significant difference was found regarding the procedure itself as well as the myocardial blush grade 'MBG' ( $p$ values $>0.05$ ) as shown in Table 3.

Regarding the angiographic data of the 2nd procedure; comparison between groups A and B in-hospital survivors ( $n=97$; group $A=48$ and group $B=49$ survivors) revealed that the thrombus resolution in group $B$ (late deferral) was significantly better than group A (early deferral); $p<0.001$, however there was no significant difference between the two groups regarding the TIMI flow as well as the MBG; $p>0.05$ as shown in Table 4 .

Comparison between the studied groups showed that median lesion length was significantly higher in group $C$ compared to both groups A and B (24 vs. 20.5, $p=0.037$ and 24 vs. $20, p=0.004$ respectively), however no significant difference was found between groups A and B; $p>0.05$, also regarding the angiographic outcome; after the 1st procedure incidence of no-reflow was significantly higher in group C than groups A and B (24\% vs. $10 \%$ and $8 \%, p=0.043$ ) while after the 2 nd procedure the incidence of no-reflow was matched between groups $\mathrm{A}$ and $\mathrm{B} ; p>0.05$ ). Final TIMI flow grade 3 and MBG grade 3 were significantly higher in group $A$ and $B$ than group C; $p=0.019$ and $<0.001$ respectively as shown in Table 5 .

Comparison between the studied groups regarding the in-hospital outcome showed that there was no significant difference between the 3 groups regarding

Table 2 Comparison between the studied groups regarding the baseline data

\begin{tabular}{|c|c|c|c|c|}
\hline Clinical data & Group $A(N=50)$ & Group B $(N=50)$ & Group C $(N=50)$ & $p$ value \\
\hline Age (years) & $50.8 \pm 9.8$ & $49.8 \pm 10.3$ & $54.0 \pm 11.0$ & 0.117 \\
\hline \multicolumn{5}{|l|}{ Risk factors } \\
\hline Male gender & $37(74 \%)$ & $38(76 \%)$ & $41(82 \%)$ & 0.610 \\
\hline $\mathrm{DM}$ & $16(32 \%)$ & $14(28 \%)$ & $17(34 \%)$ & 0.805 \\
\hline HTN & $27(54 \%)$ & $22(44 \%)$ & $25(50 \%)$ & 0.602 \\
\hline Smoking & $28(56 \%)$ & $27(54 \%)$ & $26(52 \%)$ & 0.923 \\
\hline Dyslipidemia & $15(30 \%)$ & $11(22 \%)$ & $15(30 \%)$ & 0.584 \\
\hline$I H D$ & $3(6 \%)$ & $6(12 \%)$ & $5(10 \%)$ & 0.576 \\
\hline \multicolumn{5}{|l|}{ Diagnosis } \\
\hline Anterior STEMI & $19(38 \%)$ & $29(58 \%)$ & $32(64 \%)$ & \multirow[t]{3}{*}{0.111} \\
\hline Inferior STEMI & $29(58 \%)$ & $20(40 \%)$ & $17(34 \%)$ & \\
\hline Lateral STEMI & $2(4 \%)$ & $1(2 \%)$ & $1(2 \%)$ & \\
\hline Heart rate (beat/min) & $95(90-110)$ & $95(90-110)$ & $98(90-110)$ & 0.699 \\
\hline $\mathrm{SBP}(\mathrm{mmHg})$ & $117.5(100-130)$ & $120(100-130)$ & $120(100-130)$ & 0.904 \\
\hline $\mathrm{DBP}(\mathrm{mmHg})$ & $70(60-80)$ & $75(60-80)$ & $75(60-80)$ & 0.840 \\
\hline \multicolumn{5}{|l|}{ Killip class } \\
\hline Class 1 & $29(58 \%)$ & $26(52 \%)$ & $26(52 \%)$ & \multirow[t]{3}{*}{0.342} \\
\hline Class 2 & $19(38 \%)$ & 20 (40\%) & $19(38 \%)$ & \\
\hline Class 3 & $2(4 \%)$ & $4(8 \%)$ & $5(10 \%)$ & \\
\hline Baseline EF (\%) & $40(38-46)$ & $40(38-47)$ & $40(38-47)$ & 0.831 \\
\hline Serum Creatinine (mg/dL) & $1.0(0.9-1.1)$ & $1.0(0.9-1.2)$ & $1.0(0.9-1.2)$ & 0.779 \\
\hline
\end{tabular}


Table 3 Comparison between the studied groups regarding the angiographic and procedural data of 1st procedure

\begin{tabular}{|c|c|c|c|c|}
\hline $\begin{array}{l}\text { Angiographic and procedural data of } 1 \text { st } \\
\text { procedure }\end{array}$ & $\begin{array}{l}\text { Group } A(4-16 \mathrm{~h} \text { deferral) } \\
\text { Number }=50\end{array}$ & $\begin{array}{l}\text { Group B ( } 7 \text { days deferral) } \\
\text { Number }=50\end{array}$ & $\begin{array}{l}\text { Group C (immediate) } \\
\text { Number }=50\end{array}$ & $p$ value \\
\hline \multicolumn{5}{|l|}{ IRA } \\
\hline LAD & $19(38 \%)$ & $29(58 \%)$ & $32(64 \%)$ & \multirow[t]{3}{*}{0.059} \\
\hline LCX & $9(18 \%)$ & $3(6 \%)$ & $5(10 \%)$ & \\
\hline RCA & $22(44 \%)$ & $18(36 \%)$ & $13(26 \%)$ & \\
\hline \multicolumn{5}{|l|}{ Thrombus grade at 1st procedure } \\
\hline Grade 2 & $2(4 \%)$ & $0(0 \%)$ & $3(6 \%)$ & \multirow[t]{4}{*}{0.407} \\
\hline Grade 3 & $2(4 \%)$ & $4(8 \%)$ & $9(18 \%)$ & \\
\hline Grade 4 & $35(70 \%)$ & $25(50 \%)$ & $24(48 \%)$ & \\
\hline Grade 5 & $11(22 \%)$ & $21(42 \%)$ & $14(28 \%)$ & \\
\hline \multicolumn{5}{|l|}{ Baseline TIMI flow } \\
\hline TIMI 0 & $35(70 \%)$ & $29(58 \%)$ & $33(66 \%)$ & \multirow[t]{4}{*}{1.000} \\
\hline TIMI 1 & $3(6 \%)$ & $12(24 \%)$ & $6(12 \%)$ & \\
\hline TIMI 2 & $8(16 \%)$ & $7(14 \%)$ & $8(16 \%)$ & \\
\hline TIMI 3 & $4(8 \%)$ & $2(4 \%)$ & $3(6 \%)$ & \\
\hline \multicolumn{5}{|l|}{ Procedural data } \\
\hline Balloon angioplasty & $30(60 \%)$ & $32(64 \%)$ & $32(64 \%)$ & 0.892 \\
\hline Aspiration & $12(24 \%)$ & $16(32 \%)$ & $11(22 \%)$ & 0.483 \\
\hline PCl to non-culprit & $11(22 \%)$ & $10(20 \%)$ & $5(10 \%)$ & 0.236 \\
\hline \multicolumn{5}{|l|}{ TIMI flow after 1st procedure } \\
\hline TIMI 0 & $0(0 \%)$ & $0(0 \%)$ & $6(12 \%)$ & \multirow[t]{4}{*}{0.034} \\
\hline TIMI 1 & $0(0 \%)$ & $0(0 \%)$ & $3(6 \%)$ & \\
\hline TIMI 2 & $5(10 \%)$ & $4(8 \%)$ & $3(6 \%)$ & \\
\hline TIMI 3 & $45(90 \%)$ & $46(92 \%)$ & $38(76 \%)$ & \\
\hline \multicolumn{5}{|l|}{ MBG after 1st procedure } \\
\hline Grade 0 & $19(38 \%)$ & $14(28 \%)$ & $27(54 \%)$ & \multirow[t]{4}{*}{0.224} \\
\hline Grade 1 & $12(24 \%)$ & $18(36 \%)$ & $9(18 \%)$ & \\
\hline Grade 2 & $12(24 \%)$ & $12(24 \%)$ & $7(14 \%)$ & \\
\hline Grade 3 & 7 (14\%) & $6(12 \%)$ & $7(14 \%)$ & \\
\hline
\end{tabular}

over-all MACE, bleeding and CIN; $p>0.05$. While, after 6-months, over-all MACE was significantly higher in group C than groups A and B (34.7\% vs. $14.6 \%$ and $16.3 \%$, $p=0.029)$, the most frequent event reported in each of groups $\mathrm{A}$ and $\mathrm{C}$ was heart failure (8.3\% and $14.3 \%)$ and in group B was Non-fatal MI (8.2\%) as shown in Table 6 and illustrated by Kaplan Mier curve in Fig. 1.

\section{Discussion}

To date, few studies have explored the potential benefit of withholding stent implantation in acute myocardial infarction when primary percutaneous coronary intervention (PCI) strategy was chosen [29].

Accordingly, this study was conducted aiming to compare the effects of immediate versus deferral of stenting and explore the benefits of delaying stenting in 1ry PCI and the better duration of delay after recanalization of the infarct related artery in a subset of patients with heavy thrombus burden.
We have found that the incidence of no/slow-reflow was significantly higher in the immediate stenting group as the percentage of patients with final TIMI flow grade 3 was significantly higher in both deferred stenting groups (group A and B) than in immediate stenting (group C) ( $82.2 \%$ vs. $76 \%$, respectively), the same was found with the percentage of patients with final MBG grade 3. Also, in the DEFER-STEMI study, deferral of stenting 4-16 h caused a reduction in occurrence of no-reflow when compared to immediate stenting (5.9\% vs. $28.6 \%)$ [16]. This was also consistent with Tang et al. [30] Who found a significant reduction in thrombus burden prior to stenting after 7 days of deferral, with subsequent higher percentage of final TIMI III flow in the deferral group after stenting.

In their landmark trial, DANAMI-3-DEFER, Kelbæk et al. [19] in 2016 tested deferral of stenting in a study population of patients undergoing 1ry PCI randomized to either immediate or deferred stenting, and it showed 
Table 4 Comparison between the studied groups regarding the angiographic data of the 2 nd procedure of groups $A \& B$ in-hospital survivors $(n=97)$

\begin{tabular}{lccc}
\hline $\begin{array}{l}\text { Angiographic data of } \\
\text { 2nd procedure }\end{array}$ & $\begin{array}{l}\text { Group A (4-16 h } \\
\text { deferral) } \\
\text { Number=48 }\end{array}$ & $\begin{array}{l}\text { Group B (7 days } \\
\text { deferral) } \\
\text { Number=49 }\end{array}$ & $\boldsymbol{p}$ value \\
\hline $\begin{array}{l}\text { Thrombus grade at 2nd procedure } \\
\text { Grade 0 }\end{array}$ & $3(6.3 \%)$ & $14(28.7 \%)$ & $<0.001$ \\
Grade 1 & $1(2.1 \%)$ & $6(12.2 \%)$ & \\
Grade 2 & $21(43.7 \%)$ & $25(51 \%)$ & \\
Grade 3 & $14(29.2 \%)$ & $1(2 \%)$ & \\
Grade 4 & $4(8.3 \%)$ & $2(4.1 \%)$ & \\
Grade 5 & $5(10.4 \%)$ & $1(2 \%)$ & \\
TIMI flow after 2nd procedure & $7(14.3 \%)$ & \\
TIMl 2 & $10(20.8 \%)$ & $42(85.7 \%)$ & \\
TIMl 3 & $38(79.2 \%)$ & & \\
MBG after 2nd procedure & $3(6.1 \%)$ & \\
Grade 0 & $4(8.3 \%)$ & $7(14.3 \%)$ & \\
Grade 1 & $7(14.6 \%)$ & $9(18.4 \%)$ & \\
Grade 2 & $11(22.9 \%)$ & $30(61.2 \%)$ & \\
Grade 3 & $26(54.2 \%)$ & & \\
\hline
\end{tabular}

no benefit and resulted in a class III recommendation for routine deferral of stenting in the latest guidelines.

In the current study, and others' as DEFER-STEMI trial [16], the population study selected had heavy thrombus burden (TIMI thrombus grade $\geq 2$ ), which we thought would be the subset of patients that would benefit from stent implantation deferral. $56 \%$ in our patients' population had TIMI grade 4 thrombus and $31 \%$ had TIMI grade 5 thrombus burden, with no significant difference between the 3 studied groups regarding neither baseline thrombus grade nor TIMI flow in the IRA. The angiographic findings of our trial showed that after the 1st procedure; the percentage of patients with TIMI flow grade 3 was significantly higher in groups A and B compared to group C (90\% and $92 \%$ vs. $76 \%, p$ value $=0.034)$ Also thrombus regression was evident in patients' 2 nd coronary angiography, with nearly half of the patients presented at 2 nd procedure with thrombus grade 2 . We have also found that regarding the thrombus resolution at the 2nd procedure; group B (7 days deferral) was significantly better than group A (4-16 h deferral), this delineates the only merit of the prolonged interval of deferral in group $\mathrm{B}$, leaving a longer time for the drugs to act on and help in thrombus resolution. However, after the 2nd procedure no significant difference was found between the two groups regarding the TIMI flow as well as the MBG.

In the current study, median lesion length was significantly higher in group $\mathrm{C}$ compared to each of groups $\mathrm{A}$ and group B. This was consistent with other studies as DEFER-STEMI trial [16] which showed reduced lesion length after stent deferral, however no significant difference was found between groups A and B. This is mostly caused by the spontaneous (auto-thrombolysis) and the pharmacologic induced angiographic changes in the vessel with time after deferral of stenting, resulting in shorter implanted stents with better long-term prognosis and lower rates of in-stent restenosis.

In the current study, in group A (4-16 h deferral), stenting of the IRA was avoided in 4 (8\%) patients, while in group B (7 days deferral), stenting was avoided in 10

Table 5 Comparison between the studied groups regarding the final lesion length and angiographic outcome

\begin{tabular}{|c|c|c|c|c|}
\hline Lesion length and angiographic outcome & $\begin{array}{l}\text { Group A (4-16 h } \\
\text { deferral) } \\
\text { Number }=50 \text { (48 for } 2 \text { nd } \\
\text { procedure) }\end{array}$ & $\begin{array}{l}\text { Group B ( } 7 \text { days deferral) } \\
\text { Number }=50 \text { ( } 49 \text { for } 2 \text { nd } \\
\text { procedure) }\end{array}$ & $\begin{array}{l}\text { Group C (immediate) } \\
\text { Number }=50\end{array}$ & $p$ value \\
\hline Lesion length (mm) & $20.5(18-24)$ & $20(16-25)$ & $24(20-27)$ & 0.003 \\
\hline No-reflow after 1st procedure & $5(10 \%)$ & $4(8 \%)$ & $12(24 \%)$ & 0.043 \\
\hline No-reflow after 2nd procedure & $10(20.8 \%)$ & $7(14.3 \%)$ & - & 0.396 \\
\hline \multicolumn{5}{|l|}{ Final TIMI flow } \\
\hline TIMI 0 & $0(0 \%)$ & $0(0 \%)$ & $6(12 \%)$ & \multirow[t]{4}{*}{0.019} \\
\hline TIMI 1 & $0(0 \%)$ & $0(0 \%)$ & $3(6 \%)$ & \\
\hline TIMI 2 & $10(20.8 \%)$ & $7(14.3 \%)$ & $3(6 \%)$ & \\
\hline TIMI 3 & $38(79.2 \%)$ & $42(85.7 \%)$ & $38(76 \%)$ & \\
\hline \multicolumn{5}{|l|}{ Final MBG } \\
\hline Grade 0 & $4(8.3 \%)$ & $3(6.1 \%)$ & $27(54 \%)$ & \multirow[t]{4}{*}{$<0.001$} \\
\hline Grade 1 & $7(14.6 \%)$ & $7(14.3 \%)$ & $9(18 \%)$ & \\
\hline Grade 2 & $11(22.9 \%)$ & $9(18.4 \%)$ & $7(14 \%)$ & \\
\hline Grade 3 & $26(54.2 \%)$ & $30(61.2 \%)$ & $7(14 \%)$ & \\
\hline
\end{tabular}


Table 6 Comparison between the studied groups regarding the clinical outcome

\begin{tabular}{|c|c|c|c|c|}
\hline $\begin{array}{l}\text { Clinical outcome } \\
\text { In-hospital outcome }\end{array}$ & $\begin{array}{l}\text { Group A (4-16 } \mathrm{h} \text { deferral) } \\
\text { Number }=50\end{array}$ & $\begin{array}{l}\text { Group B ( } 7 \text { days deferral) } \\
\text { Number }=50\end{array}$ & $\begin{array}{l}\text { Group C (immediate) } \\
\text { Number }=50\end{array}$ & $p$ value \\
\hline Over-all MACE & $9(18 \%)$ & $8(16 \%)$ & $10(20 \%)$ & 0.873 \\
\hline Death & $2(4 \%)$ & $1(2 \%)$ & $1(2 \%)$ & 0.773 \\
\hline Re-infarction & $3(6 \%)$ & $3(6 \%)$ & $6(12 \%)$ & 0.443 \\
\hline Arrhythmias & $5(10 \%)$ & $5(10 \%)$ & $3(6 \%)$ & 0.714 \\
\hline Cardiac decompensation & $1(2 \%)$ & $2(4 \%)$ & $2(4 \%)$ & 0.813 \\
\hline Stroke or TIA & $1(2 \%)$ & $1(2 \%)$ & $1(2 \%)$ & 1.000 \\
\hline Bleeding & $3(6 \%)$ & $3(6 \%)$ & $2(4 \%)$ & 0.876 \\
\hline $\mathrm{CIN}$ & $4(8 \%)$ & $5(10 \%)$ & $4(8 \%)$ & 0.919 \\
\hline 6-month outcome & Number $=48$ & Number $=49$ & Number $=49$ & \\
\hline Over-all MACE & $7(14.6 \%)$ & $8(16.3 \%)$ & $17(34.7 \%)$ & 0.029 \\
\hline Death & $1(2.1 \%)$ & $2(4.1 \%)$ & $3(6.1 \%)$ & 0.605 \\
\hline Non-fatal Ml & $3(6.3 \%)$ & $4(8.2 \%)$ & $5(10.2 \%)$ & 0.778 \\
\hline Arrhythmias & $3(6.3 \%)$ & $3(6.1 \%)$ & $6(12.2 \%)$ & 0.453 \\
\hline Heart failure & $4(8.3 \%)$ & $2(4.1 \%)$ & $7(14.3 \%)$ & 0.205 \\
\hline Non-fatal stroke & $1(2.1 \%)$ & $1(2 \%)$ & $2(4.1 \%)$ & 0.779 \\
\hline LVEF at 6 months (\%) & $55(50-59)$ & $53(44-58)$ & $49.5(40-55)$ & 0.009 \\
\hline Change in LVEF (\%) & $11(7-16)$ & $8(5-15)$ & $5(1.5-10)$ & 0.001 \\
\hline
\end{tabular}

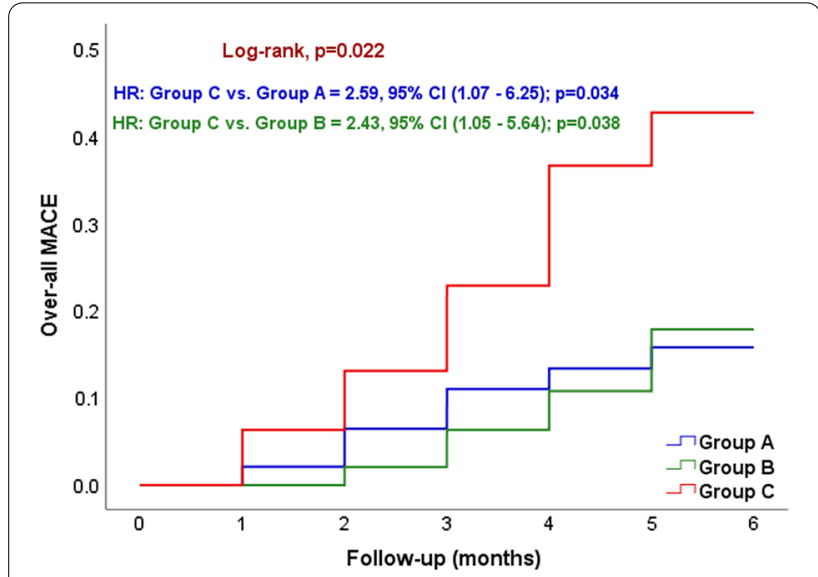

Fig. 1 Kaplan Mier survival analysis with hazard proportionate function showing the incidence rate of over-all MACE among groups A, B and C. MACE major adverse cardiovascular events

(20\%) patients, which can be explained by the thrombus resolution that occurred after deferral with the subsequent relief of the vasospasm that occurs with the heavy thrombus burden.

In DEFER-STEMI trial [16] stenting was deemed unnecessary in 3 patients in the deferral group representing 6\%, also in DANAMI-3-DEFER [19], despite the negative overall results of the Routine deferral of stenting, it showed that in the deferral group stenting was deemed unnecessary in $15 \%$ of patients.
While for the other secondary endpoints, the current study showed that regarding the in-hospital outcome; no significant difference was found between the 3 groups regarding over-all MACE, bleeding and CIN. While in respect to 6-months follow-up group $\mathrm{C}$ (immediate stenting) showed significantly higher risk of developing MACE (composite endpoint) than group A (4-16 h deferral) (34.7\% vs. 14.6\%; adjusted HR, 2.59; 95\% CI, $1.07-6.25 ; p=0.034)$, also the same group showed significantly higher risk of developing MACE than group B (7 days deferral) (34.7\% vs. 16.3\%; adjusted HR, 2.43; 95\% CI, 1.05-5.64; $p=0.038$ ). There was no statistical difference in the risk of developing MACE between groups A and $\mathrm{B}$ during the follow-up period. The most frequent event reported in group $\mathrm{C}$ was heart failure, which can be explained by the lesser percentage of achievement of TIMI grade 3 flow after revascularization of the IRA in comparison with the deferral groups.

In Tang et al. [30], no MACE occurred during period of hospitalization in both groups. After 6 months follow up, there was no significant difference in the occurrence of MACE, but lower incidence of heart failure in the deferral group was noticed (5.0\% vs. $19.1 \%$ ), which is consistent with our study as mentioned.

This was also associated in the current study with the fact that the median LVEF at 6 months was significantly lower in group $\mathrm{C}$ (immediate stenting) compared to each of groups $\mathrm{A}$ and $\mathrm{B}$ (deferred stenting) $p=0.021$, however no significant difference was found between groups $\mathrm{A}$ and $\mathrm{B}$. 
And the median change in LVEF between the initial echocardiography and the one performed 6 months later was significantly lower in group $\mathrm{C}$ compared to groups $\mathrm{A}$ and $B$, however no significant difference was found between groups A and B. In DANAMI-3-DEFER trial [19], an improvement in LVEF at 18 months with deferred stenting was observed in a smaller subset that underwent imaging. While in DEFER-STEMI trial [16], regarding the MRI findings; when compared with immediate stenting, myocardial salvage (percentage of left ventricular mass) (19.7\% [IQR: $13.8 \%$ to $26.0 \%$ ] vs. $14.7 \%$ [IQR: $8.1 \%$ to $23.2 \%$ ]) and salvage index (68\% (IQR: $54 \%$ to $82 \%$ ) vs. $56 \%$ (IQR: $31 \%$ to $72 \%$ )) were higher in the deferred stenting arm after 6 months.

Improved angiographic outcomes provided by delayed stenting, such as the higher percentage of post-PCI TIMI grade 3 flow, have been associated with a reduction in death, myocardial infarction and repeat revascularization after PCI [31]. A potential mechanical explanation for the improvement associated with delayed stenting may actually be the reduction in thrombus burden. In all the studies where quantitative coronary analysis was performed a significant reduction in thrombus burden was observed before and after the interval required for delayed stenting [30].

In the light of the results of our study, and other former studies that we mentioned, deferral of stenting is proved to be a valuable strategy in primary PCI patients with heavy thrombus burden, selection of the candidates is of great importance as DANAMI-3-DEFER [19] proved that routine deferral of stenting in primary PCI was of no value. But our study proves among others that it could be used as a bailout strategy in patients with heavy thrombus burden with resulting improved coronary flow, myocardial recovery, and reduction in lesion length or even the mere need for stent implantation.

\section{Study limitations}

The current study had the following limitations:

1. The sample size was rather small.

2. The study was conducted by several operators.

3. The patients' and angiographic characteristics might have influenced the operator to perform delayed stenting.

4. Also, cardiac MRI which was not available is a better tool for quantification of left ventricular function changes and the effects of microvascular obstruction.

\section{Conclusions}

This study suggests that; in a selected population of patients undergoing 1ry PCI, with angiographically evident high thrombus burden, stent deferral was proved to be better than immediate stenting after recanalization of IRA, in achieving TIMI III flow, reducing risk of 6 months MACE, and restoration of myocardial function. Longer deferral interval when compared to a strategy of deferral within $24 \mathrm{~h}$, did not prove to be of additional value, except for higher percentage of thrombus resolution before second procedure, which was not reflected on neither final coronary flow nor following clinical events and myocardial recovery with an extra added financial burden. So, stent deferral can be used as a bailout strategy in patients with heavy thrombus burden with resulting improved coronary flow, myocardial recovery, and reduction in lesion length or even the mere need for stent implantation.

\section{Abbreviations}

CABG: Coronary artery bypass graft; CIN: Contrast-induced nephropathy; DBP: Diastolic blood pressure; DM: Diabetes mellitus; ECG: Electrocardiogram; EF: Ejection fraction; GIT: Gastro-intestinal tract; HTN: Hypertension; IHD: Ischemic heart disease; IRA: Infarction related artery; LVEF: Left ventricular ejection fraction; MACE: Major adverse cardiovascular events; MBG: Myocardial blush grade; Ml: Myocardial infarction; PCl: Percutaneous coronary intervention; RCTs: Randomized control trials; SBP: Systolic blood pressure; SD: Standard deviation; STEMI: ST-segment elevation myocardial infarction; TIMI: Thrombolysis in myocardial infarction.

\section{Acknowledgements}

The authors gratefully acknowledge the patients who participated in this study and the staff in the cardiac catheterization Units and the Coronary Care Units of national heart institute.

\section{Authors' contributions}

AM carried out the data analysis and presentation and interpretation of the results, shared in the study design and drafting the manuscript. SR carried out data entry, writing introduction, formulating aim of the study and drafting the manuscript. HH finalized the introduction and aim of the study, formulated the conclusion and recommendations. MZ carried out the study design and coordination and developing and validating the questionnaire. MA participated in developing, validating the questionnaire and interpretation of the results as well as drafting the manuscript. MAG participated in the data analysis and interpretation of results. All authors read and approved the final version of the manuscript.

\section{Funding}

The authors received no funding for this work.

\section{Availability of data and materials}

All data generated or analysed during this study are included in this published article [and its supplementary information files].

\section{Declarations}

\section{Ethics approval and consent to participate}

The study was approved by IRB (Institutional review board) of Faculty of Medicine Assiut University and of National heart institute (the Committee's reference number is not available). Oral and written consents were obtained prior to the study, from each participant after proper orientation regarding the objectives and impact of the study. Data confidentiality was ensured throughout the whole study and protected against disclosure. The study was carried out in accordance with recommendations of the Declaration of Helsinki.

\section{Consent for publication}

Not applicable. 


\section{Competing interests}

The authors declare that they have no competing interests.

\section{Author details}

${ }^{1}$ Cardiovascular Medicine, National Heart Institute, Cairo, Egypt. ${ }^{2}$ Cardiovascular Medicine, Faculty of Medicine, Assiut University, Asyut, Egypt.

Received: 12 April 2021 Accepted: 26 August 2021

Published online: 09 September 2021

\section{References}

1. Neumann FJ, Sousa-Uva M, Ahlsson A, Alfonso F, Banning AP, Benedetto U et al (2019) 2018 ESC/EACTS guidelines on myocardial revascularization. Eur Heart J 40:87-165

2. Konijnenberg LSF, Damman P, Duncker DJ, Kloner RA, Nijveldt R, Van Geuns RJM et al (2020) Pathophysiology and diagnosis of coronary microvascular dysfunction in ST-elevation myocardial infarction. Cardiovasc Res 116:787-805

3. Harrison RW, Aggarwal A, Ou FS, Klein LW, Rumsfeld JS, Roe MT et al (2013) Incidence and outcomes of no-reflow phenomenon during percutaneous coronary intervention among patients with acute myocardial infarction. Am J Cardiol 111(2):178-184

4. Ndrepepa G, Tiroch K, Fusaro M, Keta D, Seyfarth M, Byrne RA et al (2010) 5-Year prognostic value of no-reflow phenomenon after percutaneous coronary intervention in patients with acute myocardial infarction. J Am Coll Cardiol 55(21):2383-2389

5. Stone GW, Webb J, Cox DA, Brodie BR, Qureshi M, Kalynych A et al (2005) Distal microcirculatory protection during percutaneous coronary intervention in acute ST-segment elevation myocardial infarction: a randomized controlled trial. J Am Med Assoc 293(9):1063-1072

6. Kelbæk H, Terkelsen CJ, Helqvist S, Lassen JF, Clemmensen P, Kløvgaard L et al (2008) Randomized comparison of distal protection versus conventional treatment in primary percutaneous coronary intervention. The drug elution and distal protection in ST-elevation myocardial infarction (DEDICATION) trial. J Am Coll Cardiol 51(9):899-905

7. Vlaar PJ, Svilaas T, van der Horst IC, Diercks GF, Fokkema ML, de Smet BJ et al (2008) Cardiac death and reinfarction after 1 year in the thrombus aspiration during percutaneous coronary intervention in acute myocardial infarction study (TAPAS): a 1-year follow-up study. Lancet 371(9628):1915-1920

8. Kaltoft A, Bøttcher M, Nielsen SS, Hansen HHT, Terkelsen C, Mæng M et al (2006) Routine thrombectomy in percutaneous coronary intervention for acute ST-segment-elevation myocardial infarction: a randomized, controlled trial. Circulation 114(1):40-47

9. Sianos G, Papafaklis MI, Daemen J, Vaina S, van Mieghem CA, van Domburg RT et al (2007) Angiographic stent thrombosis after routine use of drug-eluting stents in ST-segment elevation myocardial infarction. The importance of thrombus burden. J Am Coll Cardiol 50(7):573-583

10. Lim SY (2016) No-reflow phoenomenon by intracoronary thrombus in acute myocardial infarction. Chonnam Med J 52(1):38

11. Alidoosti M, Lotfi R, Lotfi-Tokaldany M, Nematipour E, Salarifar M, Poorhosseini $\mathrm{H}$ et al (2018) Correlates of the "no-reflow" or "slow-flow" phenomenon in patients undergoing primary percutaneous coronary intervention. J Tehran Heart Cent 13(3):108-114

12 Henriques JPS, Zijlstra F, Ottervanger JP, De Boer MJ, Van'T Hof AWJ, Hoorntje JCA et al (2002) Incidence and clinical significance of dista embolization during primary angioplasty for acute myocardial infarction. Eur Heart J. 23(14):1112-1117

13. Isaaz K, Robin C, Cerisier A, Lamaud M, Richard L, Da Costa A et al (2006) A new approach of primary angioplasty for ST-elevation acute myocardial infarction based on minimalist immediate mechanical intervention. Coron Artery Dis 17(3):261-269

14. Cafri C, Svirsky R, Zelingher J, Slutky O, Kobal S, Weinstein JM, Ilia R, Gilutz H (2004) Improved procedural results in coronary thrombosis are obtained with delayed percutaneous coronary interventions. J Invasive Cardiol 16(2):69-71

15. Ke D, Zhong W, Fan L, Chen L (2012) Delayed versus immediate stenting for the treatment of ST-elevation acute myocardial infarction with a high thrombus burden. Coron Artery Dis 23(7):497-506
16. Carrick D, Oldroyd KG, McEntegart M, Haig C, Petrie MC, Eteiba H et al (2014) A randomized trial of deferred stenting versus immediate stenting to prevent no- or slow-reflow in acute ST-segment elevation myocardial infarction (DEFER-STEMI). J Am Coll Cardiol 63(20):2088-2098

17. Pascal J, Veugeois A, Slama M, Rahal S, Belle L, Caussin C et al (2016) Delayed stenting for ST-elevation acute myocardial infarction in daily practice: a single-centre experience. Can J Cardiol 32(8):988-995

18 Kim JS, Lee HJ, Woong YuC et al (2016) Innovation study (impact of immediate stent implantation versus deffered stent implantation on infarct size and microvascular perfusion in patients with ST-segmentelevation myocardial infarction). Circ Cardiovasc Interv 9(12):e004101

19. Kelbæk H, Høfsten DE, Køber L, Helqvist S, Kløvgaard L, Holmvang L et al (2016) Deferred versus conventional stent implantation in patients with ST-segment elevation myocardial infarction (DANAMI 3-DEFER): an openlabel, randomised controlled trial. Lancet 387(10034):2199-2206

20. Belle L, Motreff P, Mangin L, Rangé G, Marcaggi X, Marie A et al (2016) Comparison of immediate with delayed stenting using the minimalist immediate mechanical intervention approach in acute ST-segmentelevation myocardial infarction: the MIMI study. Circ Cardiovasc Interv. 9(3):e003388

21. Meneveau N, Seronde MF, Descotes-Genon V et al (2009) Immediate versus delayed angioplasty in infarct-related arteries with TIMI III flow and ST-segment recovery: a matched comparison in acute myocardial infarction patients. Clin Res Cardiol 98:257-264

22. Kim J, Choi D, Jang Y et al (2010) Efficacy of high-dose atorvastatin loading before primary percutaneous coronary intervention in ST-segment elevation myocardial infarction: the STATIN STEMI trial. JACC CardiovasC Interv 3:332-339

23. Di P, Cannizzaro S, Parrinello G et al (2006) Is delayed facilitated percutaneous coronary intervention better than immediate in reperfused myocardial infarction? Six months follow up findings. J Thromb Thrombolysis 21:147-157

24 Grech ED (2003) Percutaneous coronary intervention. II: the procedure. BMJ 326(7399):1137-1140

25. Ibanez B, James S, Agewall S, Antunes MJ, Bucciarelli-Ducci C, Bueno Het al (2018) 2017 ESC Guidelines for the management of acute myocardial infarction in patients presenting with ST-segment elevation. Eur Heart J 39:119-177

26. Morishima I, Sone T, Mokuno S, Taga S, Shimauchi A, Oki Y et al (1995) Clinical significance of no-reflow phenomenon observed on angiography after successful treatment of acute myocardial infarction with percutaneous transluminal coronary angioplasty. Am Heart J 130(2):239-243

27. Thygesen K, Alpert JS, Jaffe AS, Chaitman BR, Bax JJ, Morrow DA, White HD, Mickley H, Crea F, Van de Werf F, Bucciarelli-Ducci C (2019) Fourth universal definition of myocardial infarction (2018). Eur Heart J 40(3):237-269

28. Guitterez NV, Diaz A, Timmis GC et al (2002) Determinants of serum creatinine trajectory in acute contrast nephropathy. J Interv Cardiol 15:349-354

29. Freixa X, Belle L, Joseph L, Tanguay JF, Souteyrand G, L'Allier PL et al (2013) Immediate vs. delayed stenting in acute myocardial infarction: a systematic review and meta-analysis. Eurolntervention 8:1207-1216

30. Tang L, Zhou S, Hu X, Fang Z, Shen X (2011) Effect of delayed vs. immediate stent implantation on myocardial perfusion and cardiac function in patients With ST-segment elevation myocardial infarction undergoing primary percutaneous intervention with thrombus aspiration. Can J Cardiol 27(5):541-547

31. Brener SJ, Westerhout CM, Fu Y, Todaro TG, Moliterno DJ, Wagner GS et al (2009) Contribution of angiographic and electrocardiographic parameters of reperfusion to prediction of mortality and morbidity after acute ST-elevation myocardial infarction: insights from the assessment of pexelizumab in acute myocardial infarction trial. Am Heart J 158(5):755-760

\section{Publisher's Note}

Springer Nature remains neutral with regard to jurisdictional claims in published maps and institutional affiliations. 